\title{
Thin Film Systems Based on Co and Cr Or Cu: Magnetoresistive Properties and Application
}

\author{
Kondrakhova D.M. , Pazukha I.M., Protsenko I.Yu. \\ Department of Applied Physic, Faculty of Electronics and Informational Technologies, Sumy State University, \\ Sumy, 2, Rymskyi-Korsakov Str. 40007, Ukraine \\ *Corresponding Author: larysa.odnodvorets@gmail.com
}

Copyright (C) 2014 Horizon Research Publishing All rights reserved.

\begin{abstract}
This article is presented the magnetoresistive properties and detailed examination of phase state and crystal structure on the as-deposited and heat-treated thin film systems $\mathrm{Co} / \mathrm{Cr} / \mathrm{Co}$ and $\mathrm{Co} / \mathrm{Cu} / \mathrm{Co}$. In this systems observed two different types of structures (multilayer and granular film), which can be used as sensing elements of magnetic sensors.
\end{abstract}

\section{Keywords Thin Film, Solid Solution,} Magnetoresistance, Magnetic Anisotropy, Coercivity, Sensitivity

\section{Introduction}

Magnetic sensors based on GMR effect characterized by quick response under low magnetic field, high sensitivity, capable of measuring high magnetic fields and not the least of the factor small size and low cost etc. Thus they have great potential for application in different fields: magnetic imaging, biosensor, contactless position detection, as reading heads in computer hard drives [1-4]. As sensing element of such sensors based on different types on thin film systems such as: structure which consist of two magnetic layers separated with non-magnetic layer; granular structures where ferromagnetic metallic nanoparticles embedded at non-magnetic metallic matrix or spin-valves consist of two magnetic layers, one of thus is fixed and another one is free, which separated with nonmagnetic layer (for fixing one of magnetic layers added antiferromagnetic layer to the top or bottom part of structure).

Today, the nanosize structures based on such magnetic materials as $\mathrm{Co}$ or $\mathrm{Fe}$ in aggregate with non-magnetic materials like $\mathrm{Cr}, \mathrm{Cu}, \mathrm{Ag} \mathrm{Au}$ etc. use extensively at formation of all types of structures listed above [5-8].

In this article, the magnetoresistive properties and probable field of application for two types of structures were investigated: three-layer structure on the base of Co and $\mathrm{Cr}$ and granular films based on $\mathrm{Co}$ and $\mathrm{Cu}$. Besides, we discuss the influence of the thicknesses or concentration on its properties, important from the application point of view.

\section{Experimental methods}

Thin film systems of both types were prepared by method of layer by layer condensation (e-beam evaporated) on sital substrate $(\mathrm{S})$ in high vacuum system $\left(p \sim 10^{-4} \mathrm{~Pa}\right)$ with average rate $\omega=1,2-4,8(\mathrm{Co})$ and $0,6-1,8 \mathrm{~nm} / \mathrm{min}(\mathrm{Cr}, \mathrm{Cu})$. The Ag layer of $5 \mathrm{~nm}$ was deposited on the top samples as protective coating. The silicon was used as a substrate material because it meets the following requirements: dielectric, temperature-stable, low coefficient of thermal expansion, the $14^{\text {th }}$ class of surface roughness and high mechanical strength. The substrate temperature was $T_{\mathrm{s}}=460$ $\mathrm{K}$ for better adhesion films to the substrate. Besides, this also gets you closer structurally perfect samples with less crystal defects. The electrical contacts on the base of two-layer systems $\mathrm{Ag} / \mathrm{Cu}$ was formed on the top of substrate before thin film systems preparation. The $\mathrm{Cu}$ bottom layer of 100-150 nm was used as auxiliary layer and Ag top layer of $30 \mathrm{~nm}$, which characterized by high inertness and conductivity, was used as contact layer.
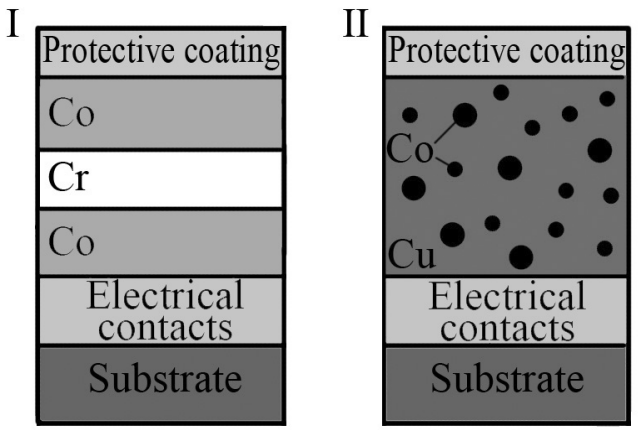

Figure 1. The structures of two types of samples, which were used at investigation: I - multilayer systems; II - granular films

Thus two series of samples were prepared: (I) three layer systems $\operatorname{Co}(5) / \operatorname{Cr}\left(d_{\mathrm{Cr}}\right) / \operatorname{Co}(20) / \mathrm{S}$ (the thicknesses of top and bottom layers of Co remain constant and the thickness of $\mathrm{Cr}$ layer changes in the range from 3 to $20 \mathrm{~nm}$ ); (II) three layer systems $\mathrm{Co} / \mathrm{Cu} / \mathrm{Co} / \mathrm{S}$ atoms on basis of which granular structures have been prepared (the common concentration of Co atoms was equal $\mathrm{cCo}=62-88$ at.\%). The schematic 
structures of two types of samples are presented at Fig.1.

The study of magnetoresistive properties was carried out with using software-hardware complex with current-in-plane geometries in an external magnetic field from 0 до $500 \mathrm{mT}$ at room temperature according the methods, which describe at work [9]. The measurement of magnetoresistance (MR) was carried out in three geometries: perpendicular, transverse and longitudinal. The value of magnetoresistance has been calculated as

$$
M R=\frac{\left(R(B)-R\left(B_{S}\right)\right)}{R\left(B_{S}\right)} \cdot 100 \%,
$$

where $R(B)$ and $R(B s)$ are resistance of thin film samples at a given and saturated field respectively.

To study the effect of temperature on phase state, structural characteristics and magnetoresistive properties of thin film samples the heat treatment was carried out to annealing temperatures $\mathrm{Ta}=700$ or 800 (to analyze the effect of the phase transition hcp-Co $\rightarrow$ fcc-Co, which occurs at 690 $\mathrm{K}$, on magnetoresistive properties) and $1000 \mathrm{~K}$ (influence of temperature on the stability of sensitive elements, which can be made on the base of the chosen film systems). The annealing duration carried out by the scheme «heating $\rightarrow$ excerpt for $20 \mathrm{~min} \rightarrow$ cooling to room temperature» with using the computerized complex, which described at work [10].

Structural and phase state investigation were made by using TEM and diffraction measurements on the transmission electron microscope TEM-125K.

\section{Experimental Results}

In earlier studies have repeatedly stated that the creation of effective sensing elements based on the type of structures $\mathrm{Me} 1 / \mathrm{Me} 2 / \mathrm{Me} 1 / \mathrm{S}$ is necessary to conduct comprehensive studies of magnetoresistive properties, structural and phase state. The detailed analysis of the phase state and the crystal structure film systems showed the following. The phase state of film systems $\mathrm{Co} / \mathrm{Cr} / \mathrm{Co} / \mathrm{S}$ after condensation corresponds to bcc-Cr + hcp-Co and crystalline structure has nanoscale character. The diffraction lines d111 and d200 from fcc-Co, which observed at room temperature (Fig. 2a), are not associated with the formation of fcc-Co crystallites as a result of the phase size effect, and with formation of stacking faults at hcp-Co (low temperature phase) as well as in bulk samples [11]. After annealing to $800 \mathrm{~K}$ the change of phase composition does not occur, there is only a slight increase of crystallite size. At $\mathrm{Ta} \geq 900 \mathrm{~K}$ the thin film $\mathrm{Cr}$ almost completely oxidized to the composition of $\mathrm{Cr} 2 \mathrm{O} 3$ (Fig. 2c). Thus, dependences, which presented at Fig. 4, described the magnetoresistive properties of system $\mathrm{Co} /(\mathrm{bcc}-\mathrm{Cr}+$ $\mathrm{Cr} 2 \mathrm{O} 3) / \mathrm{Co} / \mathrm{S}$.

In the case of systems based on $\mathrm{Co}$ and $\mathrm{Cu}$ has place the formation of solid solution $(\mathrm{Co}, \mathrm{Cu})$ on the base of $\mathrm{Cu}$ fcc lattice at a condensation stage. The annealing to $700 \mathrm{~K}$ occurs to polymorphic transition hcp-Co $\rightarrow$ fcc-Co. Partial disintegration of solid solution with formation granules of Co in solid solution matrix occurs at annealing to $850 \mathrm{~K}$ (the diffraction rings of hcp-Co fixed at electron-diffraction pattern (Fig. 3c)). Thus the purpose of formation granular films was attained.

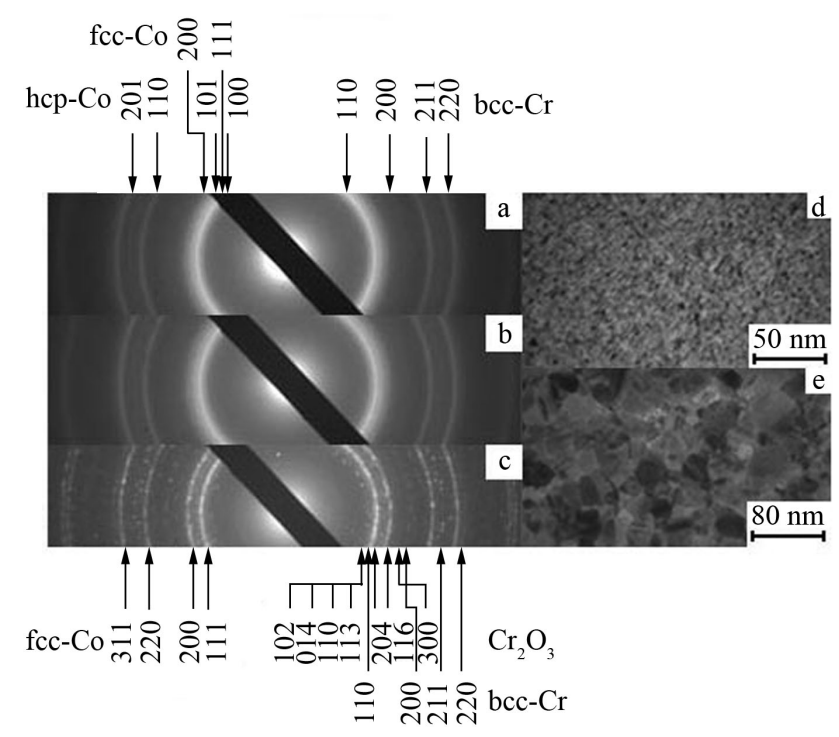

Figure 2. Diffraction pattern (a-c) and crystalline structure (d, e) of film systems $\operatorname{Co}(5) / \mathrm{Cr}(5) / \mathrm{Co}(20) / \mathrm{S}$ as deposited (a, d) and after annealing to $T_{\mathrm{a}}=$ $800 \mathrm{~K}(\mathrm{~b}), 1000 \mathrm{~K}(\mathrm{c}, \mathrm{e})$

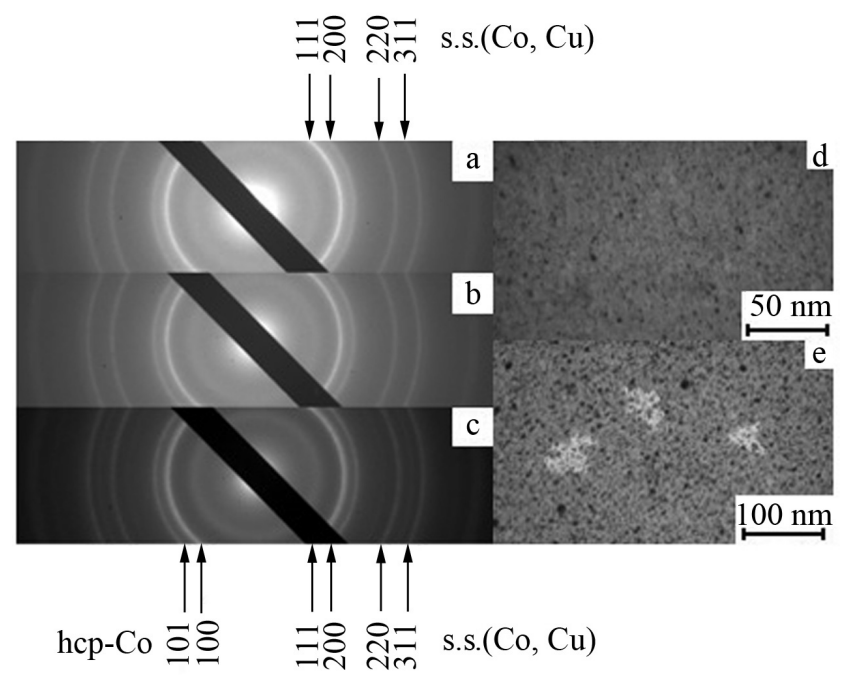

Figure 3. Diffraction pattern (a-c) and crystalline structure (d, e) of film systems $\mathrm{Co}(22) \mathrm{Cu}(17) \mathrm{Co}(20) / \mathrm{S}$ as deposited (a, d) and after annealing to $T_{\mathrm{a}}$ $=700 \mathrm{~K}(\mathrm{~b}), 850 \mathrm{~K}(\mathrm{c}, \mathrm{e})$

Fig. 4 and 5 shows the magnetoresistance curves after condensation and heat-treated typical of the $\mathrm{Co} / \mathrm{Cr} / \mathrm{Co} / \mathrm{S}$ and $\mathrm{Co} / \mathrm{Cu} / \mathrm{Co} / \mathrm{S}$ systems. The results of calculation of MR value and coecivity are presented in Table 1 . The characteristic properties of this data are following. The magnetoresistance effect in film systems $\mathrm{Co} / \mathrm{Cr} / \mathrm{Co} / \mathrm{S}$ (Fig. 4) characterized by not great value of MR $(0.1-0.3 \%)$, here with maximum value $0.4 \%$ obtained in perpendicular geometry after heat treated to $800 \mathrm{~K}$ at the thickness of interlayer $\mathrm{dCr}=20 \mathrm{~nm}$. In 
addition, sensing elements on the base of $\mathrm{Co}$ and $\mathrm{Cr}$ attributed by sufficiently large values of coercivity $\mathrm{Bc}(>100$ $\mathrm{mT})$ at $\mathrm{Co}$ atom concentration $\mathrm{cCo}=56-63$ at. $\%$ in perpendicular geometry as after condensation so as after heat treated to $800 \mathrm{~K}$. At increasing cCo take place decreasing of $\mathrm{Bc}$ value. Though, it should be noted that at high-temperature annealing to $1000 \mathrm{~K}$ observed significant increasing of coercivity for all range of concentration and all types of measurement geometries. For example, for film system $\mathrm{Co}(5) / \mathrm{Cr}(13) / \mathrm{Co}(20) / \mathrm{S}$ the value of $\mathrm{Bc}$ increases from $23(300 \mathrm{~K})$ to $200 \mathrm{mT}(1000 \mathrm{~K})$ in perpendicular geometry. The increasing of coercivity as a result of phase state changing of sample.
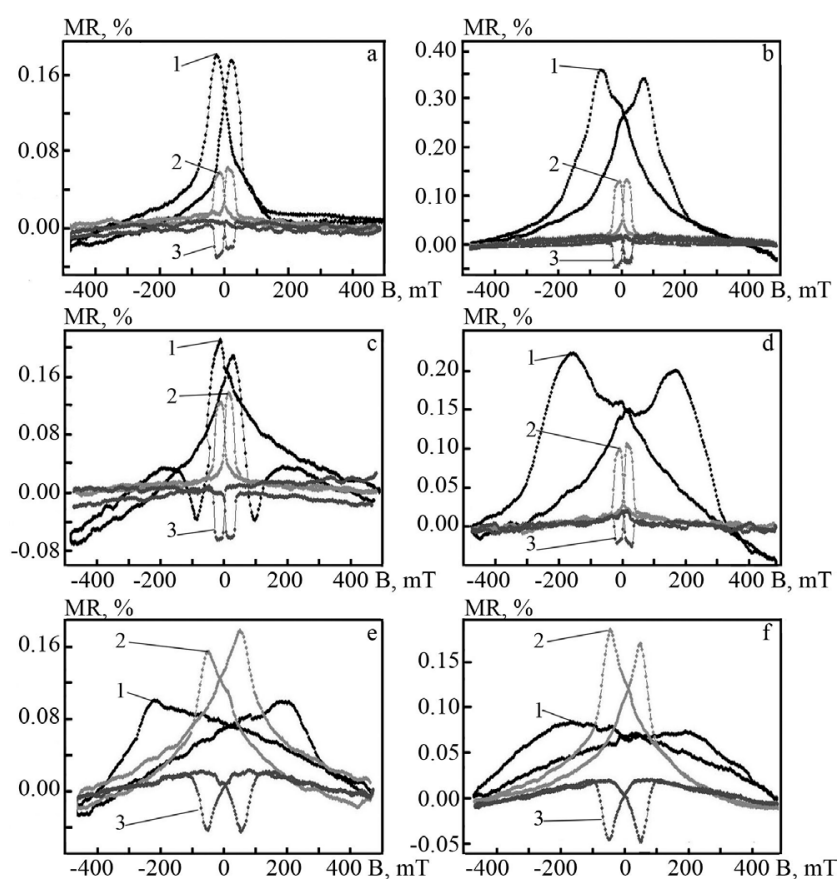

Figure 4. Magnetoresistance dependence versus applied field for film systems $\mathrm{Co}(5) / \mathrm{Cr}(5) / \mathrm{Co}(20) / \mathrm{S}(\mathrm{a}, \mathrm{c}, \mathrm{e})$ and $\mathrm{Co}(5) / \mathrm{Cr}(13) / \mathrm{Co}(20) / \mathrm{S}(\mathrm{b}, \mathrm{d}, \mathrm{f})$ after condensation $(\mathrm{a}, \mathrm{b})$ and heat treated to $800 \mathrm{~K}(\mathrm{c}, \mathrm{d})$ and $1000 \mathrm{~K}(\mathrm{e}, \mathrm{f})$. Magnetic field lying in perpendicular (1), longitudinal (2), transverse (3) geometries

Thus at work [5] has been reported that the in-plane coercivity can be increased by thermal treatment from 1 to 24 $\mathrm{mT}$. According to work [5] structural and magnetic properties of structures based on $\mathrm{Co}$ and $\mathrm{Cr}$ are good candidate for using as sensing elements of magnetic sensors and as hard spin injectors. Peculiarity of hysteresis of field dependence is availability double peak (see, for example, magnetoresistance dependence vs. applied field for film system $\mathrm{Co}(5) / \mathrm{Cr}(13) / \mathrm{Co}(20) / \mathrm{S}$ (Fig. 4b, d, f). It's can be explained by alternate magnetic reversal of Co layers [12]. It should be noted, that for film systems $\mathrm{Co} / \mathrm{Cr} / \mathrm{Co} / \mathrm{S}$ in all range of interlayer thickness take place anisotropy of magnetorsistance at transfer to longitudinal geometry of measurement. The value of anisotropy increases at decreases of magnetic component atom concentration.
The value of the magnetoresistance for structures of second type depends of total concentration of Co atom and changes from 0.2 to $0.4 \%$ at increasing cCo from 60 to 87 at.\%. Besides, magnetoresistive properties of granular films based on $\mathrm{Co}$ and $\mathrm{Cu}$ slowly depend on heat treated. The annealing to $700 \mathrm{~K}$ leads to slight decrease of the values of MR and saturated field Bs. At the same time heat treatment of samples $\mathrm{Co}(14) / \mathrm{Cu}(9) / \mathrm{Co}(14) / \mathrm{S}$ (Fig. 5d) reduces to decrease of the magnetoresistance effect in the perpendicular geometry and its increase in other geometries. The value of Bs changes in a similar way (from 140 to $24 \mathrm{mT}$ - in the perpendicular and from 35 to $39 \mathrm{mT}$ - in longitudinal geometry).
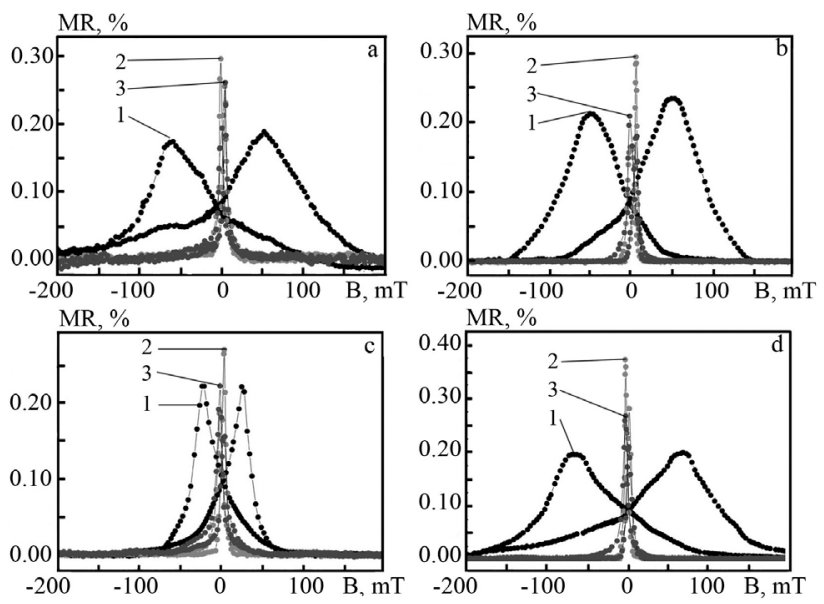

Figure 5. Magnetoresistance dependence versus applied field for film systems $\mathrm{Co}(14) / \mathrm{Cu}(7) / \mathrm{Co}(14) / \mathrm{S}(\mathrm{a}, \mathrm{c})$ and $\mathrm{Co}(14) / \mathrm{Cu}(9) / \mathrm{Co}(14) / \mathrm{S}(\mathrm{b}, \mathrm{d})$ after condensation $(\mathrm{a}, \mathrm{b})$ and heat treated to $700 \mathrm{~K}(\mathrm{c}, \mathrm{d})$

In forming the structure of the sensing element of considerable importance is the ability of the sensor to respond to changes in the magnetic field irrespective of measurement geometry and the value of the sensitivity to the magnetic field $\left(S_{\mathrm{B}}\right)$. Depending on the application, the sensor sensitive element should have high sensitivity and to provide a rapid response to changes in sensor input signal (e.g., instantaneous closure / opening of the circuit in automation) or medium in order to be able to provide high accuracy of measurement the detection of weak fields.

The maximum value of the sensitivity of the film system to the magnetic field was determined by the equation $\left(\Delta \mathrm{R} / \mathrm{R}\left(\mathrm{B}_{\mathrm{s}}\right)\right)_{\max } / \Delta \mathrm{B}$. The results of SB calculations for the samples of both types after condensation and heat treated are presented in Table 2.

The highest value of magnetic sensitivity for film systems based on $\mathrm{Co}$ and $\mathrm{Cr}$ for a sample of $\mathrm{Co}(5) / \mathrm{Cr}(20) / \mathrm{Co}(20) / \mathrm{S}$ is $19.8 \% / \mathrm{T}$ in the perpendicular geometry of the measurement; for film systems based on $\mathrm{Co}$ and $\mathrm{Cu}$ for a sample of $\mathrm{Co}(14) / \mathrm{Cu}(9) / \mathrm{Co}(14) / \mathrm{S}-21.5 \% / \mathrm{T}$ in the transverse geometry of the measurement. Note that those structures can be used in analog and digital circuits for fast response to changing magnetic flux. 
Table 1. The value of MR and coercivity $\left(B_{\mathrm{c}}\right)$ for film systems of both types after condensation and heat treated

\begin{tabular}{|c|c|c|c|c|c|c|c|c|}
\hline \multirow{3}{*}{ Film system } & \multirow{3}{*}{$\begin{array}{l}c_{\mathrm{Co}} \\
\text { at. } \%\end{array}$} & \multirow{3}{*}{$T, \mathrm{~K}$} & \multicolumn{3}{|c|}{ MR, \% } & \multicolumn{3}{|c|}{$B_{\mathrm{c}}, \mathrm{mT}$} \\
\hline & & & \multicolumn{3}{|c|}{ measurement geometry } & \multicolumn{3}{|c|}{ measurement geometry } \\
\hline & & & perpend. & transverse & longitud. & perpend. & transverse & longitud. \\
\hline \multirow{3}{*}{$\mathrm{Co}(5) / \mathrm{Cr}(5) / \mathrm{Co}(20) / \mathrm{S}$} & \multirow{3}{*}{83} & 300 & 0.18 & 0.06 & -0.03 & 23.06 & 13.21 & 32.62 \\
\hline & & 800 & 0.21 & 0.14 & -0.06 & 90.74 & 13.51 & 20.39 \\
\hline & & 1000 & 0.10 & 0.15 & -0.04 & 199.72 & 49.69 & 52.25 \\
\hline \multirow{2}{*}{$\mathrm{Co}(14) / \mathrm{Cu}(7) / \mathrm{Co}(14) / \mathrm{S}$} & \multirow{2}{*}{81} & 300 & 0.19 & 0.30 & 0.26 & 140 & 29 & 35 \\
\hline & & 700 & 0.22 & 0.27 & 0.22 & 24 & 37 & 39 \\
\hline \multirow{2}{*}{$\mathrm{Co}(14) / \mathrm{Cu}(9) / \mathrm{Co}(14) / \mathrm{S}$} & \multirow{2}{*}{77} & 300 & 0.24 & 0.30 & 0.21 & 200 & 14 & 30 \\
\hline & & 700 & 0.20 & 0.37 & 0.27 & 134 & 37 & 44 \\
\hline \multirow{3}{*}{$\mathrm{Co}(5) / \mathrm{Cr}(10) / \mathrm{Co}(20) / \mathrm{S}$} & \multirow{3}{*}{71} & 300 & 0.13 & 0.04 & -0.02 & 12.53 & 17.00 & 15.18 \\
\hline & & 800 & 0.22 & 0.12 & -0.01 & 26.92 & 13.31 & 22.13 \\
\hline & & 1000 & 0.08 & 0.13 & -0.03 & 183.96 & 72.15 & 42.18 \\
\hline \multirow{2}{*}{$\mathrm{Co}(20) / \mathrm{Cu}(25) / \mathrm{Co}(25) / \mathrm{S}$} & \multirow{2}{*}{66} & 300 & 0.34 & 0.26 & 0.26 & 100 & 35 & 37 \\
\hline & & 700 & 0.25 & 0.26 & 0.25 & 100 & 22 & 39 \\
\hline \multirow{3}{*}{$\mathrm{Co}(5) / \mathrm{Cr}(15) / \mathrm{Co}(20) / \mathrm{S}$} & \multirow{3}{*}{63} & 300 & 0.19 & 0.13 & -0.04 & 129.55 & 13.96 & 21.04 \\
\hline & & 800 & 0.27 & 0.20 & -0.10 & 149.66 & 16.57 & 20.16 \\
\hline & & 1000 & 0.04 & 0.06 & -0.02 & 67.98 & 54.01 & 73.02 \\
\hline \multirow{3}{*}{$\mathrm{Co}(5) / \mathrm{Cr}(20) / \mathrm{Co}(20) / \mathrm{S}$} & \multirow{3}{*}{56} & 300 & 0.26 & 0.10 & -0.06 & 139.47 & 16.06 & 15.75 \\
\hline & & 800 & 0.40 & 0.16 & -0.07 & 20.16 & 15.21 & 17.93 \\
\hline & & 1000 & 0.02 & 0.02 & 0.03 & 117.22 & 37.12 & 67.49 \\
\hline
\end{tabular}

Table 2. The value of $S_{\mathrm{B}}$ for film systems of both types after condensation and heat treated

\begin{tabular}{|c|c|c|c|c|c|}
\hline \multirow{3}{*}{ Film system } & \multirow{3}{*}{$\begin{array}{l}c_{\mathrm{Co}} \\
\text { at. } \%\end{array}$} & \multirow{3}{*}{$T, \mathrm{~K}$} & \multicolumn{3}{|c|}{$S_{\mathrm{B}}, \% / \mathrm{T}$} \\
\hline & & & \multicolumn{3}{|c|}{ measurement geometry } \\
\hline & & & perpendicular & transverse & longitudinal \\
\hline \multirow{3}{*}{$\mathrm{Co}(5) / \operatorname{Cr}(5) / \mathrm{Co}(20) / \mathrm{S}$} & \multirow{3}{*}{83} & 300 & 7.8 & 4.5 & 0.9 \\
\hline & & 800 & 10.0 & 10.4 & 3.2 \\
\hline & & 1000 & 0.5 & 3.0 & 0.8 \\
\hline \multirow{2}{*}{$\mathrm{Co}(14) / \mathrm{Cu}(7) / \mathrm{Co}(14) / \mathrm{S}$} & \multirow{2}{*}{81} & 300 & 1.3 & 10.1 & 7.3 \\
\hline & & 700 & 9.3 & 7.3 & 5.7 \\
\hline \multirow{2}{*}{$\mathrm{Co}(14) / \mathrm{Cu}(9) / \mathrm{Co}(14) / \mathrm{S}$} & \multirow{2}{*}{77} & 300 & 1.2 & 21.5 & 6.9 \\
\hline & & 700 & 1.5 & 10.1 & 6.1 \\
\hline \multirow{3}{*}{$\mathrm{Co}(5) / \mathrm{Cr}(10) / \mathrm{Co}(20) / \mathrm{S}$} & \multirow{3}{*}{71} & 300 & 1.1 & 2.4 & 1.2 \\
\hline & & 800 & 8.2 & 9.0 & 0.2 \\
\hline & & 1000 & 0.5 & 1.8 & 0.7 \\
\hline \multirow{2}{*}{$\mathrm{Co}(20) / \mathrm{Cu}(25) / \mathrm{Co}(25) / \mathrm{S}$} & \multirow{2}{*}{66} & 300 & 3.4 & 7.5 & 7.0 \\
\hline & & 700 & 2.5 & 11.8 & 6.5 \\
\hline \multirow{3}{*}{$\mathrm{Co}(5) / \mathrm{Cr}(15) / \mathrm{Co}(20) / \mathrm{S}$} & \multirow{3}{*}{63} & 300 & 10.4 & 9.3 & 1.7 \\
\hline & & 800 & 18.7 & 12.0 & 4.9 \\
\hline & & 1000 & 0.5 & 1.1 & 0.2 \\
\hline \multirow{3}{*}{$\mathrm{Co}(5) / \mathrm{Cr}(20) / \mathrm{Co}(20) / \mathrm{S}$} & \multirow{3}{*}{56} & 300 & 6.2 & 6.2 & 3.8 \\
\hline & & 800 & 19.8 & 10.5 & 3.9 \\
\hline & & 1000 & 0.1 & 0.5 & 0.4 \\
\hline
\end{tabular}


Analysis of the data for the other samples also allows identifying possible areas of application of the magnetic field sensor based on them. Since the sensitivity to magnetic field, in most cases not exceeding $10 \% / \mathrm{T}$, such a structure is more suitable for detection of weak magnetic fields.

\section{Conclusions}

The results of investigation of phase state of thin film system of two types show that the samples based on Co and $\mathrm{Cr}$ has two-phase state and in the samples based on Co and $\mathrm{Cu}$ the take place formation nanostructured solid solution with granules of Co. So the first one of systems allows realizing the multilayer structures and second one granulated structures for production sensing elements of magnetic field sensors. Notes, both types of systems depending on the concentration of components can be used in analog and digital circuits for rapid response to changing magnetic flux or when creating a stable sensor for detecting weak magnetic fields. Besides, the phase states of systems slowly depend on heat treated to $800 \mathrm{~K}$, it allows to exclude the influence of temperature on the working characteristics of the sensors.

\section{Acknowledgements}

Work carried out with financial support from the Ministry of Education and Science of Ukraine (Grant № 0112U001381, 2012 - 2014).

\section{REFERENCES}

[1] Mitra Djamal, Ramli. Development of sensors based on giant magnetoresistance material, Proc. Eng., Vol.32, 60-68, 2012.

[2] Stobiecki F., Urbaniak M., Szymanski B., Lucinski T., Schmidt M., Aleksiejew J. Ni80Fe20/Au/Co/Au multilayers as magnetic field sensors, Materials Science-Poland, Vol.24,
No3, 833-838, 2006.

[3] Nepijko S.A., Kutnyakhov D., Odnodvorets L.V., Protsenko S.I. Sensor and microelectronic elements based on nanoscale granular systems, J.Nanopart. Res., Vol.12, No3, 6263-6281, 2011.

[4] Zhang H., Wang W. Microfabrication and test of a magnetic field sensor using electrodeposited thin film of giant magnetoresistive $(\mathrm{Cu} / \mathrm{Co}) \mathrm{x}$ multilayers, Microsystem Technologies, Vol.9, No6-7, 436-440, 2003.

[5] Chiolerio A., Martino P., Coisson M., Allia P. Vector magnetisation measurements on thermally evaporated $\mathrm{CoCr}$ multilayers and solid solutions for spintronic applications, Journal of Magnetism and Magnetic Materials, Vol.31, 3099-3103, 2009.

[6] A. Polewko-Klim, S. Uba, L. Uba. Influence of anisotropy and interparticle interactions on the coercivity and remanence in superparamagnetic $\mathrm{Fe} / \mathrm{Au}$ multilayers, Journal of Magnetism and Magnetic Materials, Vol.324, 1193-1200, 2012.

[7] V.V. Hiep, N. Chau, D.M. Hong, N.H. Luong. High coercivity and giant magnetoresistance of $\mathrm{CoAg}, \mathrm{CoCu}$ granular films Original Research Article, Journal of Magnetism and Magnetic Materials, Vol.310, No2, 2524-2526, 2007.

[8] Cheshko I.V., Protsenko S.I., Odnodvorets L.V., Shifalovich P. Magnetooptical and magnetoresistive properties of $\mathrm{Co} / \mathrm{Cu}(\mathrm{Au})$-based spin-valve structures, Technical Phys. Lett. Vol.35, No10, 903-905, 2009.

[9] Demydenko M.H., Protsenko S.I., Kostyuk D.M., Cheshko I.V. Magnetoresistive properties of the spin-valve structures based on $\mathrm{Co}$ and $\mathrm{Cu}$ or $\mathrm{Au}, \mathrm{J}$. Nano- Electron Phys., Vol.3, No4, 106-113, 2011.

[10] Zlenko V.O., Protsenko S.I., Safarich R. Automated complex research thermoresistive properties of nanostructured film systems, J. Nano- Electron Phys., Vol.1, No2, 29-35, 2009.

[11] Gorbacheva T.B. Rentgenografia tverdych splavov. Moskwa: Metallurgia, 103, 1985.

[12] V.O. Vas'kovskiy, A.A. Yuvchenko, V.N. Lepalovsky, S.M. Schegoleva, A.V. Svalov. Elements of a granular state in the multilayer films of $\mathrm{Co} / \mathrm{Cu}$, The Phys. of Metals and Metallography, Vol.93, No3, 43-49, 2002. 